Received: 3 August 2018

Revision received: 21 October 2018

Copyright $@ 2019$ ESTP

Accepted: 16 February 2019

www.estp.com

DOI 10.12738/estp.2019.3.005 • July $2019 \cdot 19(3) \bullet 65-85$

Article

\title{
The Effect of Instructor's Learning Modes on Deep Approach to Student Learning and Learning Outcomes
}

\author{
Michael Yao-Ping Peng \\ Yango University, China
}

\author{
Chun Chun Chen \\ Beijing Union University, China
}

\begin{abstract}
The multiple characteristics of students motivate universities to provide a learning environment that integrates teaching and learning in one and to strengthen students' learning motivation through student-oriented learning mode, so as to enhance students' input in study. In this study, the concept of depth learning is adopted to measure students' input in study and to explore the effectiveness of specialized learning modes and students' learning outcomes. Therefore, this study aimed to analyse a sample of 2,340 students from 16 Taiwanese higher education institutions by structural equation modelling. The results showed that specialized learning modes (explorative and exploitative learning) could increase deep approach to learning. Explorative and exploitative learning have positive effects on learning outcomes (cognitive gains and non-cognitive gains). Deep approach to learning has significant mediating effect between learning modes and learning outcomes.
\end{abstract}

\section{Keywords}

Deep approach to learning $・$ Exploitative learning $\bullet$ Explorative learning $\cdot$ Higher education $\cdot$ Student learning outcomes $\bullet$ Structural equation model

Correspondence to Chun Chun Chen, Assistant Research Fellow, School of Management, Beijing Union University, Beijing 100101, China. Email: 317791001@163.com

Citation: Peng, Y. P. M., \& Chen, C. C. (2019). The effect of instructor's learning modes on deep approach to student learning and learning outcomes. Educational Sciences: Theory \& Practice, 19(3), 65 - 85. http://dx.doi.org/10.12738/estp.2019.3.005 
In recent years, the issue of globalization has attracted much attention. No matter the industrial circle or the academic circle are committing to working with the international development tendency. Its purpose is to reduce the impact brought by the fluctuations of global economic climate, changes in industrial context, and the demands for diversified talents. For this purpose, the higher education and the cultivation of talents play an important role, and both of them are also the basis of the national economic development (Choi \& Rhee, 2014). The higher education has changed from traditional elite education to the popular education (Taylor, Webber, \& Jacobs, 2013). It has caused problems such as low teaching quality and insufficient competitiveness, although the reform of higher education policy provides more opportunities for students to receive education, becoming a hidden concern for the development of higher education (Marginson, 2011; Shin \& Harman, 2009). Coupled with the worse economy and the declining number of children, these problems have severely affected the recruitment and enrolment, retention and dropout rates of universities. Therefore, the quality and performance of running a university has become an important basis for the establishment of reputation and development characteristics of universities. In particular, it is required to return to the essence of university education, focus on the student learning outcomes, i.e., replacing the development direction that the performance assessment focuses on the mass production graduates with talent cultivation that takes high quality as the standard to plan courses, teach and review the learning achievement, and that combines learning with employment. Recent studies on higher education have pointed out that student learning outcomes can be significantly improved through the increased teaching quality, curriculum design innovation, and optimization of resource equipment (Maringe \& Sing, 2014; Pike, Kuh, McCormick, Ethington, \& Smart, 2011; Pike, Smart, \& Ethington, 2012).

Studies show that higher education institutions have the greatest impact on student learning, experience and perception of students throughout the learning process, including instructors' teaching quality, interaction between instructors and students, students' academic performance, and participation in the campus and off-campus activities (Pike et al., 2012), making it exert a powerful social influence (Snyder, 1971). The most important thing is to stimulate students' initiative in participating in activities and obtaining learning experiences after the commitment to learning.

The way and strategy of learning engagement is the key to gain experience and turn it into their own knowledge and capabilities. Since most of the factors affecting student performance are indirect factors (Pascarella \& Terenzini, 2005; Terenzini \& Pascarella, 1991), it is necessary to verify the essence of these indirect effects (Terenzini \& Pascarella, 1991). Therefore, Smart, Feldman, and Ethington (2000) regard students' learning engagement as an important mediating variable. This mediating variable can verify the relationship between academic development and learning outcomes. Scholars believe that learning engagement means learning behaviours that students engage in university and their appropriateness for higher education institutions and discipline experience (Kuh, Kinzie, Buckley, Bridges, \& Hayek, 2006). Therefore, the way of learning engagement lies in the development of generic student competencies, such as problem-solving, communication, and interpersonal skills (Choi \& Rhee, 2014), which also play an important role in the learning process. Marton and Säljö (1976) proposed a deep process that can effectively differentiate students' responses to learning tasks. Deep approach to learning (DAL) is the preferred learning method for most people. It shows that students can explore massage other than information itself, enabling it to become the key to an effective learning environment. Students who use the DAL are able to process, retain, integrate, and transfer important information more quickly than students with surface approaches to learning (Ramsden, 2003). In addition, this study adopts the learning process stimulus $\rightarrow$ cognition $\rightarrow$ outcomes in the cognitive learning theory as the research framework, arguing that the DAL plays an important role in instructor's learning modes and student learning outcomes. To sum up, this study will 
focus the relationship of DAL in student learning motivation and student learning outcomes and will explore it with a more complete research framework.

According to the above explanations, this study intends to propose relevant research contributions based on the following theoretical gaps: (i) applying cognitive learning theory to college student learning, and exploring the effectiveness of learning modes; (ii) building a conceptual framework to explore antecedents of DAL from the perspective of students to cultivate and establish effectiveness of DAL, and verify the relevance between the two; (iii) adopting cross-cultural view to explore the mediating role of DAL in Asian context.

\section{Student Learning Outcomes}

Learning outcome is an indicator for judging students' learning achievements. The measurement of learning outcomes aims to enable students to understand their own learning status and serves as a basis for instructors and students to improve the learning efficiency and effectiveness (Guay, Ratelle, \& Chanal, 2008). Research shows that learning is a process that leads to the evolution of behaviour through activities or experiences (i.e., stating a strong social influence through the participation of the curriculum and the interaction of instructors or peers) as well as the performance of students reflected by certain assessment indicators after a period of participation in the learning activities (Pike et al., 2011, 2012). Assessment indicators of learning outcomes can be formal and standardized tests, as well as informal or subjective perceptions of instructors or students (Chen, Wang, Wei, Fwu, \& Hwang, 2009), or changes in certain behaviours (Guay et al., 2008). This is because the learning outcomes of students can be used to verify the contribution of higher education institutions in the goal achievement, provide reasons for the continued existence of institutions, and determine whether learning activities should continue (Maringe \& Sing, 2014; Pike et al., 2011, 2012).

The psychological and motivational perspective helps to provide insights in the process of student learning outcomes. Guay et al. (2008) believes that the main idea of self-determination theory assumes that students' learning induced by autonomous motivation will produce different types of positive outcomes such as behavioural outcomes, cognitive outcomes, and affective outcomes. Pike et al. (2011) discuss how educational spending and the level of student engagement in higher education institutions can affect student performance, that is, two variables that measure student learning outcomes: cognitive gains and noncognitive gains. Cognitive gains mean that the university experience of students is conducive to general education, writing and speaking, quantitative analysis, and critical thinking, giving rise to significant improvement and progress. Non-cognitive gains test students' responses to self-awareness, collaboration, ethical standards, and citizen/community engagement. Although scholars do not measure the effectiveness of learning in the same way because of the different research purposes, research samples and research motivations, Pike, Smart, Kuh, and Hayek (2006) pointed out that previous studies mostly test students' level of learning at different time points, such as freshman, sophomore, junior, and senior. However, combining these students in a single analysis may bias the research results. That is, the relationship between variables may have differences in learning outcomes due to different grades. Therefore, this study satisfies this issue by controlling student grades, reducing the degree of variation in the variables among samples, referencing the measurement method used by Pike et al. (2011), and using cognitive gains and non-cognitive gains as indicators to measure students' learning outcomes.

\section{Explorative and Exploitative Learning}

In studies of student learning, scholars build new and richer understandings and discussions based on a large amount of known knowledge. Through the observation of other people's behaviours, learners 
began to try to develop the knowledge base required to complete a specific task (Oleson \& Hora, 2014). Therefore, to develop students' learning goals, we must increase their participation in learning activities, so that all their learning potentials can be tapped. Moreover, universities keep a close relationship with industries, so that students must acquire knowledge and skills for employment before hunting a job (Corbett, 2005; Philip, Unruh, Lachman, \& Pawlina, 2008). Such knowledge and skills can be divided into two categories (Hmelo-Silver, Duncan, \& Chinn, 2007). One is the practice capability (i.e., a high sensitivity to the imagery thinking, emphasizing the soft skills such as organization, communication, environmental adaptation and opportunity mastery), and the other is the academic capability (i.e., a high logical thinking ability, emphasizing the deductive process of argumentation, induction, and theoretical innovation). Thus, this study, on the basis of the dualism, divides the learning mode into explorative learning and the exploitative learning from the perspectives of theory and practice, so as to find the most appropriate pathway for the development of DAL from the above two learning modes that are inspired by teachers.

Explorative learning is essentially identical with the inquiry learning, emphasizing on the ability of students to raise questions, collect and analyse materials, and construct evidence-based comments while learning professional knowledge and skills of a subject (Hmelo-Silver et al., 2007). Because explorative learning can strengthen student's problem examination and inquiry in professional disciplines, it focuses on the combination and creation of professional domain knowledge and hopes to put forward new knowledge and new insights on the basis of the original theory.

Exploitative learning has similar theories with experience-learning and problem-based learning, emphasizing the conscious sensory cognitive processes, in which learners transform experience into personal knowledge through the interaction of individuals and the environment, conflict, and problem solving (Kolb, 1984). Corbett (2005) believes that the individual's knowledge stock is static, and knowledge can only be created by applying knowledge into learning activities through a cognitive mechanism. Therefore, the exploitative learning emphasizes students' acquisition of experience and practices with different sources, and integrates experience, response, thinking, and action patterns to form unique new insights and new knowledge of an individual, enhancing the individual's flexibility and adaptability against the real world. In this case, this study suggests that in the process of student learning, both explorative and exploitative learning have positive impacts on student learning outcomes, and both the student learning mode and the curriculum teaching construction cover the two learning methods (Hmelo-Silver et al., 2007). Thus, in terms of the essence or operation of definitions, the two are only different in engagement proportions and priorities.

The effect of prior knowledge systems on shaping cognition, behaviour, and identity have been widely recognized in cognitive psychology and educational research, and more previous studies focus on learning and development (Hummel \& Randler, 2012; Tella, 2007; White, Thomas, Johnston, \& Hyde, 2008). In the study of learning science in the past few decades, scholars have built new and richer understandings and discussions based on a large amount of known knowledge. In particular, through observational research of other people's behaviours, learners began to try to develop the knowledge base required to complete a specific task (Oleson \& Hora, 2014). These knowledge learning activities may be shaped by the influence of tutors, immediate family members, knowledge of learning methods and subject matter, and practical knowledge in the classroom (Pike et al., 2012). More importantly, these learning methods and belief systems have been impressed in the students' minds before they enter the classroom. In the initial learning phase, students continue to observe the behaviours of instructors as an apprentice, but they do not systematically conduct research or imitation. Instead, a set of acceptable behavioural scripts is provided through the recalling of episodic memories (Nespor, 1987). 
Therefore, the basic goal of developing student learning is to increase student's engagement in learning activities and to use the full learning potential of students, but not just through traditional teaching methods. Student engagement can be regarded as the quality of learning experience (Pace, 1984). The amount of physical and mental energy required to engage in academic experience (Astin, 1993) depends on the role of the student in the learning process, but not the passive subject affected by the environment (Choi $\&$ Rhee, 2014). From the perspective of psychology, apart from energy, involvement and professional efficacy, one of the important components of learning engagement is absorption (Schaufeli, Salanova, González-Romá, \& Bakker, 2002). Specifically, according to the definition of Schaufeli and Salanova (2007), even in a difficult environment, students have a high degree of energy and mental resilience, willingness and persistence to complete schoolwork (vigour), have a powerful desire to participate in learning assignments, recognize the perceptions (dedication) such as significance, enthusiasm, inspiration and challenges, and are completely and happily obsessed with their own schoolwork (absorption). Therefore, explorative and exploitative learning play an important role in the process of knowledge acquisition. The two learning modes have a control feedback mechanism and a process of constantly correcting mistakes. The two learning modes also update the individual memory of students through the conscious or unconscious learning, so as to develop the time concept, stress management and other skills (Hmelo-Silver et al., 2007; Li, Greenberg, \& Nicholls, 2007) of students through their understanding, theoretical deduction and principle digging of professional knowledge, and promise to bring students' learning to a deeper understanding and meaning.

In short, the studies of student learning indicate that students can study in the educational context, and instructors can design specific and feasible courses and implementation plans through teaching content, teaching methods, attitude development and instructor-student interaction (Corbett, 2005; Hmelo-Silver et al., 2007). Therefore, the classification of learning mode in this study is an educational situation based on the application of theoretical knowledge exploration and practical experience application, with a purpose of exploring the relationship between learning mode and learning outcomes. The results should help colleges and their instructors understand the optimal curriculum planning and activities. On the basis above, this study proposes the following hypotheses:

H1: Exploitative learning has a positive correlation with deep approach to learning.

$\mathrm{H} 2$ : Explorative learning has a positive correlation with deep approach to learning.

H3: Exploitative learning has a positive correlation with student learning outcomes (like cognitive gains and non-cognitive gains).

H4: Explorative learning has a positive correlation with student learning outcomes (both cognitive and non-cognitive gains).

\section{Deep Approach to Learning}

In related research on student engagement, Campbell and Cabrera (2014) proposed that an important measurement tool for measuring student engagement is the National Survey of Student Engagement (NSSE), which had been used by more than 1,400 institutions to understand effective internal education practices. This survey tool has several important measurement variables (e.g., the measurement construct of DAL), which are used to measure the internal validity and construct validity of the variable, and to test whether the variable can effectively predict the student's grade point average (GPA).

In recent years, DAL has gained the attention of scholars and institutions in the studies on higher education and has been used to develop students' learning potential. Most studies on the DAL originate from the university study conducted by Marton and Säljö (1976). Its key arguments include that students can use 
different methods to study, and the learning methods are closely related to learning outcomes (Ramsden, 2003). There are two recognized learning methods: the surface approach and the deep approach (Beatie, Collins, \& McInnes, 1997). Students who use the surface approach focus on the essential contents of information and emphasize the learning and memory by rote (Laird, Shoup, Kuh, \& Schwarz, 2008; Tagg, 2003). In contrast, students with the deep approach not only focus on the essential contents, but also emphasize the fundamental meaning of information, interconnection, integration of knowledge, and metacognition (Biggs \& Tang, 2011; Pascarella, Wang, Trolian, \& Blaich, 2013). And its development process is to develop the deep and concrete teaching mode through the cooperation of students, colleges, universities and instructors, such as inducing positive student responses, building student prior knowledge, and teaching more ideas and interconnectedness between ideas (Biggs \& Tang, 2011; Campbell \& Cabrera, 2014). Scholars agree that the DAL is reflected in the use of different learning strategies by students' personal commitment to understanding of teaching materials and information, like extensive reading, integration of different resources and joint discussion of ideas. DAL devotes to discussing how to link the independent pieces of information to vast constructs or models, and applies knowledge to the real-world situations (Biggs, 2003; Ramsden, 2003; Tagg, 2003). Therefore, the nature of DAL is to integrate, and aggregate previously learned information and turn it into a part of personal thinking, thereby examining new phenomena and activities from different perspectives and perspectives (Ramsden, 2003; Tagg, 2003).

In terms of the measurement of the DAL, the most widely used tools are Biggs' Questionnaire Process Questionnaire (SPQ) and National Student Engagement Survey (NSSE). The two student learning outcome assessments designed for the higher education sector have been updated to cover three major approach scales (deep, surface, and achievement approaches), and six motivational and strategic core scales through texts updating and reductions of questions in recent years, combined with new learning studies (Biggs, Kember, \& Leung, 2001; Laird, Shoup, \& Kuh, 2006; Laird et al., 2008; Pascarella et al., 2013; Reason, Cox, McIntosh, \& Terenzini, 2010). NSSE DAL scale has been quite mature, including the verification of internal and predictive validity. For example, Laird et al. (2006), and Campbell and Cabrera (2014) conducted a validated factor analysis of NSSE multivariate organizational data and obtained the high-quality construct validity and fitness indicators (RMSEA, CFI, TLI). In terms of DAL, measurement variables include higher-order learning, integrative learning, and reflective learning (Biggs \& Tang, 2011; Campbell \& Cabrera, 2014; Pascarella et al., 2013). The higher-order learning emphasizes the degree to which students believe that their curriculum can bring advanced thinking skills, for example, analysing the basic elements of an idea, experience or theory, and combining ideas, information or experience with new more complex interpretations, and putting forward its own discussion on the value of information and the application of practical problems. Integrative learning includes the participation of student activities in various fields, and it integrates ideas and diverse viewpoints from various sources, such as the ability of discussing ideas and viewpoints with other students on different opinions in academic writings. The central concept of reflective learning is that students learn and extend their understanding and comprehension by studying their own ideas, and finally apply their new knowledge to life (Laird et al., 2008; Pascarella et al., 2013). Based on the research objectives and research objects and referencing the study of Laird et al. (2008), this study takes the high-order learning, integrative learning, and reflective learning as measurement variables for the DAL.

Literatures show that the learning outcomes achieved by the DAL are better than that achieved by the surface approach to learning. But these literatures only focus on the comparison between the two learning approaches and the discussion on whether the DAL can effectively improve students' learning outcomes has been the focus of studies of scholars in recent years. For example, Laird et al. (2008) discuss 
the importance of DAL in different contexts and mention that the relevance between the DAL and the student learning outcomes may be weak or inconspicuous in engineering. However, some other scholars believe that there is still a positive relationship between the two (Greene, Miller, Crowson, Duke, \& Akey, 2004; Reason et al., 2010), such as in academic achievement. Liem, Lau, and Nie (2008) studied the relationship between the DAL and the learning outcomes, as well as the relationship between the surface learning and the learning outcomes based on the language disciplines of Singaporean students. The research results showed that there was a positive relationship between the DAL and the learning outcomes, but a negative relationship between the surface approach to learning and the learning outcomes. This also reflects that in the education system with a well-developed assessment mechanism, students tend to adopt a DAL strategy to gain more explicit feedback and effectiveness. On the basis of Aristotle's argument on phronesis or practical wisdom, through the principle of general knowledge and the application of ideas, learning of such knowledge will help students face particular situations, understand and internalize new information and improve their knowledge, skills and capabilities (Oleson \& Hora, 2014). Moreover, clear and systematic course guidance will enable students to focus not only on the acquisition of knowledge or facts, but also on the promotion of substantive learning and understanding of their underlying meaning (Laird et al., 2006). All these are contributed to the improvement of students' critical thinking skills and cognitive needs (Pascarella et al., 2013). On the basis above, this study proposes the following hypotheses:

H5: Deep approach to learning has a positive relationship with student learning outcomes.

H5a: Deep approach to learning has a positive relationship with cognitive gains.

H5b: Deep approach to learning has a positive relationship with non-cognitive gains.

Based on the above inference, the research structure proposed in this study is shown in Figure 1 below:

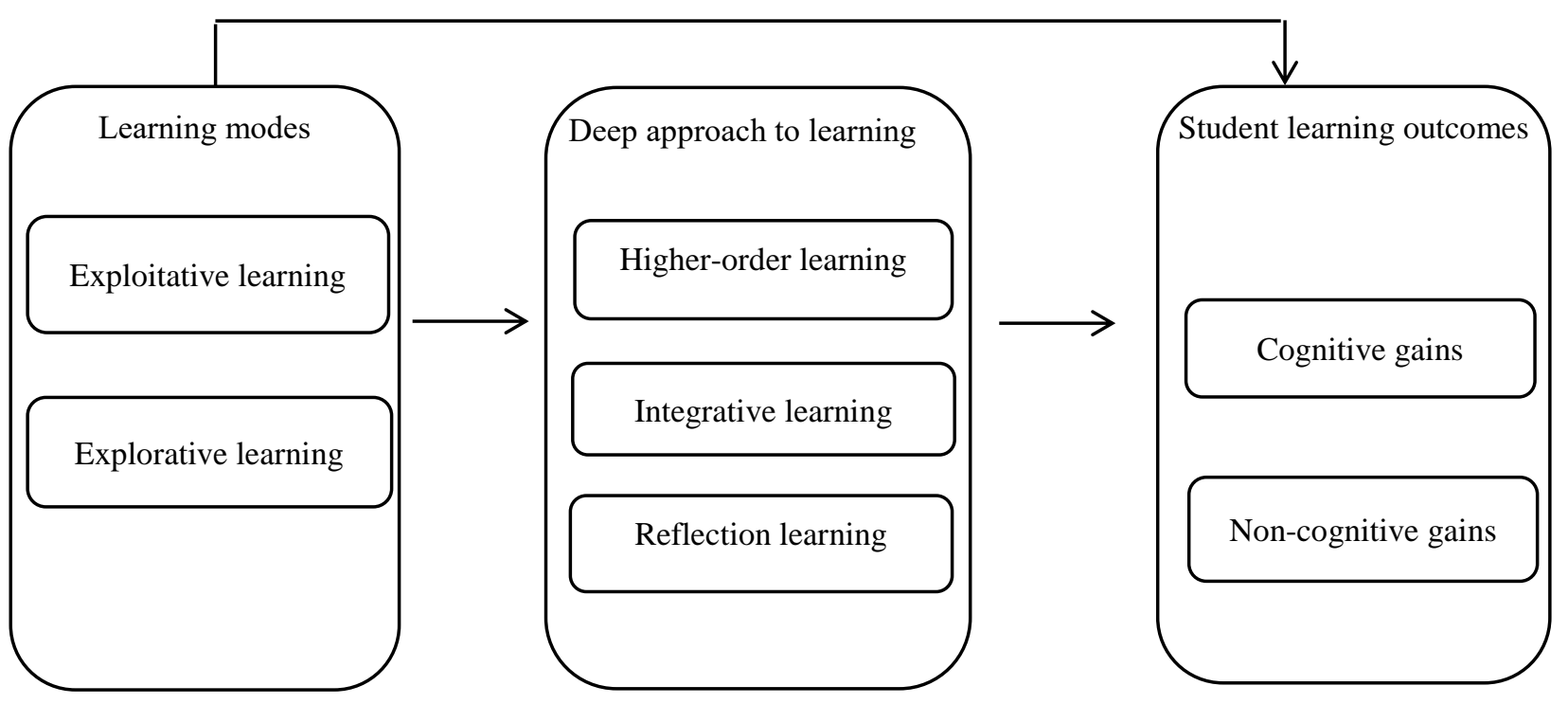

Figure 1. Research framework

This study explores the factors affecting student learning outcomes by learning theories, and examines the relationship among learning motivation, engagement and outcomes, thereby understanding the direction and connotation to be considered by higher education institutions to improve student learning outcomes. 


\section{Method}

\section{Participants}

Most of the previous researches have focused on the development of variables and scales, such as the test of DAL scales, and the verification of the relationship between deep learning and learning outcomes and the relationship between learning motivation and learning outcomes (Campbell \& Cabrera, 2014; Cole, Feild, \& Harris, 2004; Hummel \& Randler, 2012; Pascarella et al., 2013). But few studies explored the course of student learning and development by a more complete framework, especially in the context of higher education. Therefore, the study had sampled higher education institutions in all regions of Taiwan (including North, Central, and South) and consider all systems such as public and private, technical and general universities. In addition, the study also includes the subsidy for the teaching and research grants of the Ministry of Education as sampling conditions. The receiving of subsidies of higher education institutions means that their scales and directions of teaching mode and university affairs development have been recognized by relevant professional scholars and government agencies, so they are appropriately representative in the research topic about student learning outcomes. Sixteen institutions were involved in the purposive sampling. A total of 2,354 students were invited to complete questionnaires. As freshmen have a relatively low perception of the learning environment and learning activities, questionnaires are mainly targeted at sophomores, juniors and seniors. Fourteen invalid questionnaires were abandoned, and the remaining 2,340 questionnaires were analysed as valid samples.

Of all valid samples, $44.4 \%$ of students were male. In terms of grade distribution, $48.7 \%$ of students are sophomores, $38.9 \%$ are juniors, and $10.8 \%$ are seniors. Furthermore, most students have less than 5 hours of self-study per week (62.0\%), followed by 6-10 hours (26.3\%). Finally, for the generality o the analysis, this study simplifies professional disciplines. A total of $65.8 \%$ of the subjects' major in social science, and $34.2 \%$ major in natural science.

\section{Instruments}

In terms of the learning modes, instructors use different learning modes to promote students' active learning and help them achieve better learning outcomes. Therefore, this study divides learning modes into explorative learning and exploitative learning through duality. The explorative learning is based on the Explorative Learning Scale proposed by Philip et al. (2008). The items of the original scale are designed for the professional subjects of medical students. In order to increase the generality of the scale, this study consolidates 10 items of the original scale into 8 items. The exploitative learning adopts the Learning Scale proposed by $\mathrm{Li}$ et al. (2007), including 10 items such as career preparation, traditional educational goals, use of time, personal involvement, and satisfaction.

Deep approach to learning is used to integrate and summarize the previously learned information and turn it into a part of personal thinking to examine new phenomena and activities from different perspectives and point of views. The DAL is evaluated by three scales developed by Campbell and Cabrera (2014), Laird et al. (2006, 2008), and Pascarella et al. (2013) on the basis of NSSE items completed in the student samples, including higher-order learning, integrative learning, and reflective learning. According to the definition and operation of Laird et al. (2006, 2008) and Pascarella et al. (2013), the higher-order learning is measured by four items, the integrative learning consists of five items, and the reflective learning includes two items.

The student learning outcomes can be described from two levels: cognitive gains and non-cognitive gains. This study uses the Cognitive Benefit Scale proposed by Pike et al. (2011). The cognitive gains scale contains nine items that ask students to indicate the level of progress in the process of school learning, 
covering general education, effective writing and oral expression, quantitative analysis, and critical thinking. The non-cognitive gains come from students' responses and cognition to self-understanding, teamwork, development of ethical standards, and citizen/community engagement, including seven items. All items mentioned above use the Likert 7 -point scale $(1=$ totally disagree $; 7=$ totally agree $)$.

\section{Procedure}

This was a cross-sectional study whose research framework and survey instrument have been approved by Institutional Review Board of University of Taipei. The researchers contacted with the colleges and teachers who were willing to receive the questionnaire by telephone and email first. The survey packages were sent by post to students of 16 colleges. Each survey package contained a covering letter explaining the survey purpose, a survey instrument and a postage-paid envelope. Before filling out the questionnaires, students have been asked to understand the right of attending survey to ensure research ethical aspects.

\section{Data analysis}

In order to gauge validity, this study employed confirmatory factor analysis (CFA) using AMOS 22.0 to verify the construct validity (both convergent and discriminant) of scales. Hair, Black, Babin, Anderson, and Tatham (2010) recommended convergent validity criteria as follows: standardized factor loading higher than .50, average variance extracted (AVE) above .50, and composite reliability (CR) above .70. The evaluation standard for discriminant validity is the square root of AVE for one dimension greater than the correlation coefficient with any other dimension(s).

For the examination of model fit, Bagozzi and Yi (1988) believe that the size of the sample should be considered. They suggest that the model fit should be measured by the ratio of $\chi^{2}$ against its degree of freedom, generally not exceeding 3 (Hair et al., 2010). In addition, other important statistical indicators (as the ratio of $\chi^{2}$ against its degree of freedom less than 3, GFI, AGFI, NFI, CFI, and IFI more than .90, RMSEA less than .08, and PNFI greater than .50) are also considered (Jöreskog \& Sörbom, 1993).

Multi-group testing was combined with Bootstrap to gradually control the pattern parameters of the groups, including unconstrained, measurement weights, structural weights, structural covariance, structural residuals, and measurement residuals. The nested models developed from different limitations $\chi^{2}$ difference quantity to make significance analysis, in order to determine the reasonability of those parameters in controlling the two groups.

In this study, SEM is used to detect the relationship between variables in the model, and there are many items in the consideration of certain facet scales. If a single question is used as the observation indicator for analysis, the model will become complicated and the number of samples required for analysis will also swell. In addition, some questions may deviate significantly from normal distribution, resulting in a low fitting ratio. Therefore, on the basis of relevant literatures, this study uses item parcelling for SEM (Hau \& Marsh, 2004; Little, Cunningham, Shahar, \& Widaman 2002). That is to say, the items with the highest and lowest loads in the research aspects are combined. The items with the second highest and second lowest loads are combined, and so on.

\section{Results}

All scales used in the study were found to be reliable, with Cronbach's $\alpha$ ranging from .83 to .96 . As Table 1 indicates, all three criteria for convergent validity were met, and correlation coefficients were 
all less than the square root of the AVE within one dimension, suggesting that each dimension in this study had good discriminant validity.

Table 1. Reliability and validity analysis

\begin{tabular}{lcccccccccc}
\hline & 1 & 2 & 3 & 4 & 5 & 6 & 7 & 8 & 9 & 10 \\
\hline 1. Career preparation & .81 & & & & & & & & & \\
2. Traditional educational goals & $.78^{* *}$ & .81 & & & & & & & \\
3. Use of time & $.54^{* *}$ & $.62^{* *}$ & .80 & & & & & & \\
4. Personal involvement and satisfaction & $.59^{* *}$ & $.66^{* *}$ & $.73^{* *}$ & .78 & & & & & \\
5. Explorative teaching & $.67^{* * *}$ & $.73^{* *}$ & $.58^{* *}$ & $.62^{* *}$ & .81 & & & & \\
6. Higher-order Learning & $.45^{* *}$ & $.47^{* *}$ & $.39^{* * *}$ & $.44^{* *}$ & $.54^{* *}$ & .82 & & & \\
7. Integrative learning & $.45^{* *}$ & $.48^{* *}$ & $.46^{* *}$ & $.52^{* *}$ & $.55^{* *}$ & $.69^{* *}$ & .68 & & & \\
8. Reflective learning & $.37^{* * *}$ & $.38^{* * *}$ & $.29^{* *}$ & $.34^{* *}$ & $.45^{* *}$ & $.58^{* *}$ & $.60^{* *}$ & .79 & & \\
9. Cognitive gains & $.60^{* *}$ & $.63^{* *}$ & $.56^{* * *}$ & $.61^{* *}$ & $.67^{* * *}$ & $.66^{* * *}$ & $.66^{* *}$ & $.54^{* *}$ & .64 & \\
10. Non-cognitive gains & $.52^{* *}$ & $.54^{* *}$ & $.49^{* *}$ & $.53^{* *}$ & $.59^{* *}$ & $.56^{* *}$ & $.54^{* *}$ & $.52^{* *}$ & $.67^{* *}$ & .66 \\
Mean & 4.81 & 4.81 & 4.58 & 4.54 & 4.91 & 5.06 & 4.68 & 5.17 & 4.85 & 5.04 \\
SD & 1.06 & 0.98 & 1.13 & 1.05 & 0.90 & 0.92 & 0.91 & 1.00 & 0.82 & 0.88 \\
Crobach's $\alpha$ & .80 & .87 & .79 & .75 & .94 & .89 & .79 & .77 & .86 & .84 \\
AVE & .66 & .65 & .64 & .60 & .65 & .67 & .46 & .62 & .41 & .43 \\
CR & .80 & .88 & .78 & .75 & .94 & .89 & .81 & .76 & .86 & .82 \\
\hline
\end{tabular}

Note: $* * p<.001$; In Italics, the square root of AVE; SD = Standard Deviation; AVE = Average Variance Extracted; CR = Composite Reliability.

In this study, the structural model is established for the measurement model of each potential variable mentioned above according to the research structure, and the mode fit of the structural equation model examining theory is adopted. Examining the structural model, Table 2 shows a good fit index to the model. The linear structure model is shown in Figure 2.

Table 2. Structure model goodness of fit index

\begin{tabular}{lcc}
\hline Fit indices & Measurement standard & Results \\
\hline$\chi^{2} /$ degree of freedom & $<3.00$ & 2.94 \\
Goodness of Fit Index (GFI) & $>.90$ & .99 \\
Adjusted Goodness of Fit Index (AGFI) & $>.90$ & .98 \\
Root Mean Square Error of Approximation (RMSEA) & $<.05$ & .03 \\
Normed Fit Index (NFI) & $>.90$ & .99 \\
Comparative Fit Index (CFI) & $>.90$ & .99 \\
Incremental Fit Index (IFI) & $>.90$ & .99 \\
Parsimonious Normed Fit Index (PNFI) & $>.50$ & .64 \\
\hline
\end{tabular}

\section{Multi-group Testing}

The measurement pattern is confirmed to be stable. But in order to avoid the data-driven pattern and theory from being overgeneralized, the suggestions of Hair et al. (2010) were taken to divide the sample 
data into two groups based on gender (1257 female students and 1083 male students). The results are shown in Table 3 and indicates that the value of each pattern mode of $\chi^{2} / d f$ ranges from 2.92 to 3.06, the RMSEA ranges between .030 and .029 , and ECVI is in $90 \%$ of the confidence interval. Table 3 also indicates that the value of weighted measurement model, weighted structure model, covariance structure model, and residual structure model $\chi^{2}$ has reached up to a significant level, which shows that the model has good between-group invariance. In addition, the NFI added value of each model is less than .05 which is in accordance with the recommended standard of Little (1997). Therefore, the framework and the conclusion of this research will present a good generalized validity.

Table 3. Multi-group testing

\begin{tabular}{lcccccccc}
\hline Model & $\chi^{2}$ & $d f$ & $\chi^{2} / d f$ & $p$ & $R M S E A$ & NFI & ECVI & $.90 C I$ \\
\hline 1. Unconstrained & 708.76 & 232 & 3.06 & .000 & .030 & .98 & .430 & $(.397 \sim .466)$ \\
2. Measurement weights & 716.77 & 246 & 2.91 & .000 & .029 & .98 & .421 & $(.389 \sim .457)$ \\
3. Structural weights & 738.07 & 254 & 2.91 & .000 & .029 & .98 & .423 & $(.390 \sim .460)$ \\
4. Structural covariances & 750.15 & 256 & 2.93 & .000 & .029 & .98 & .427 & $(.393 \sim .464)$ \\
5. Structural residuals & 803.83 & 275 & 2.92 & .000 & .029 & .98 & .434 & $(.399 \sim .472)$ \\
2-1 & 8.01 & 14 & & .889 & & .00 & & \\
3-1 & 29.31 & 22 & & .136 & & .00 & & \\
4-1 & 41.39 & 24 & & .015 & & .00 & & \\
5-1 & 95.07 & 43 & & .000 & & .00 & & \\
\hline
\end{tabular}

\section{Hypotheses Testing of Structural Model}

The results of the study are shown in Figure 2. The path coefficient of DAL in the exploitative education is $.41(p<.001)$. Hypothesis H1 is supported, which complies with the views of other scholars, showing that the higher-level students feel the instructors' exploitative learning mode, the more chances for students to engage in the deep learning will be. The path coefficient of deep learning to instructor's explorative learning is $.31(p<.001)$. Hypothesis $\mathrm{H} 2$ is supported, showing that the higher frequency students feel the instructor's use of explorative learning mode, the more chances to improve student's ability to develop a DAL will be. The path coefficients of exploitative learning against cognitive and non-cognitive gains are $.50(p<.001)$ and $.64(p<.001)$, respectively, showing that the higher the degree of students depending on the exploitative learning, the more chances to improve the student learning outcomes will be. Therefore, the hypothesis $\mathrm{H} 3$ is supported. However, the path coefficients of the explorative learning against cognitive gains and non-cognitive gains are -.07 $(p<.05)$ and $-.13(p<.01)$, respectively, showing that instructors' continuous use of explorative learning mode will negatively reduce the student learning outcomes. This result is contrary to the hypothesis deduced in this study, so hypothesis H4 is not supported. The path coefficients of the student engagement in the DAL against cognitive and non-cognitive gains are $.56(p<.001)$ and $.41(p<.001)$, respectively, meaning that the shape and construction of the DAL can positively improve student learning outcomes, so H5a and H5b are also supported.

\section{Mediating Effect Testing of Deep Approach to Learning}

The above research found that the relationship between constructs in this study was significantly positive, except the negative significance between the explorative learning and the cognitive and noncognitive gains. To further explore more valuable insights from the research results, and considering that the previous studies have rarely used the DAL as an mediating variable, it is necessary to present a more 
experiential student learning outcomes through a complete DAL among exploitative learning, explorative learning and student learning outcomes in the process of constructing students' DAL in the context of higher education.

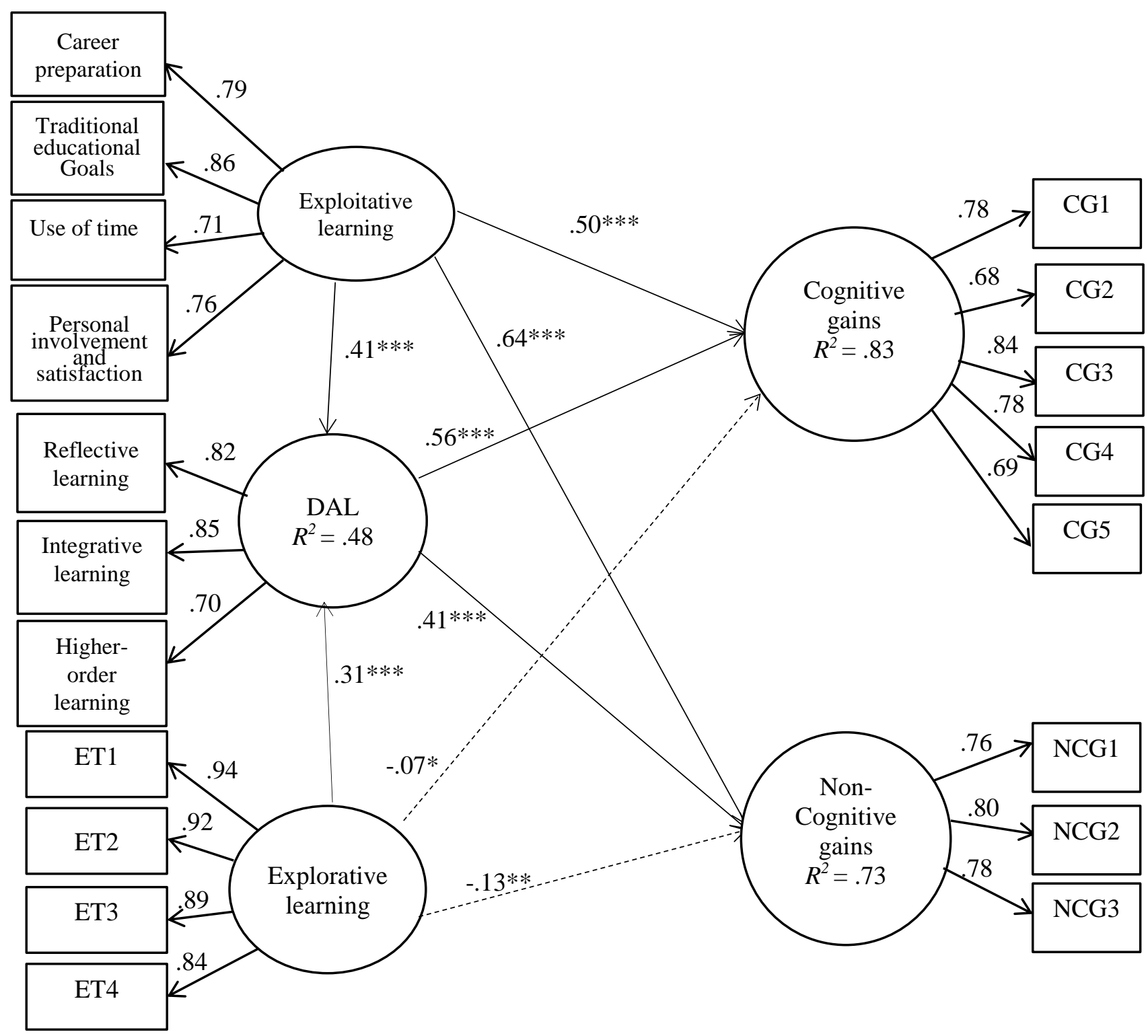

Figure 2. Path coefficient of the structural mode

In this study, the standardized effect size of direct, indirect and total effects of constructs are summarized in Table 4. It is known from Table 4 that there are four paths for the mediating effect test of $\mathrm{DAL}:$ exploitative learning $\rightarrow \mathrm{DAL} \rightarrow$ cognitive gains, exploitative learning $\rightarrow \mathrm{DAL} \rightarrow$ non-cognitive gains, explorative learning $\rightarrow \mathrm{DAL} \rightarrow$ cognitive gains, explorative learning $\rightarrow \mathrm{DAL} \rightarrow$ non-cognitive gains. The indirect effect values of the four paths are $.23, .17, .17$, and .13 , respectively. Therefore, on the basis of the suggestions proposed by Shrout and Bolger (2002), this study uses the ratio of indirect effect to total effect as an assessment indicator of the indirect effect intensity. Among them, the indirect effect (-.07) of DAL in the explorative learning and the cognitive gain/non-cognitive gains is much greater than the direct effect (- 
.13). DAL is confirmed to have a complete mediating effect in explorative learning and student learning outcomes. Furthermore, although the intensity of indirect effect of DAL in the exploitative learning and the cognitive gain/non-cognitive gains is not higher than the direct effect, it still has some mediating effects. Moreover, to further test the mediating effect, this study uses the Sobel test (Sobel, 1982), and calculates the path coefficient and the standard error according to the recommendations of Preacher and Hayes (2004). That is, when the $\mathrm{Z}$ value is greater than 1.96 , the mediating effect is significant. The study found that the DAL has significant mediating effect in the paths exploitative learning $\rightarrow$ DAL $\rightarrow$ cognitive gains $(Z=8.45)$, exploitative learning $\rightarrow \mathrm{DAL} \rightarrow$ non-cognitive gains $(Z=7.54)$, explorative learning $\rightarrow \mathrm{DAL} \rightarrow$ cognitive gains $(Z=7.89)$, and explorative learning $\rightarrow \mathrm{DAL} \rightarrow$ non-cognitive gains $(Z=7.13)$.

Table 4. Standardized effect values of direct, indirect and total effects between constructs

\begin{tabular}{llccc}
\hline Construct & Effect & Deep approach to learning & Cognitive gains & Non-cognitive gains \\
\hline Exploitative learning & Direct effect & $.405(.044)$ & $.498(.037)$ & $.637(.052)$ \\
& Indirect effect & ------- & .225 & .165 \\
& Total effect & .405 & .723 & .803 \\
Explorative learning & Direct effect & $.314(.037)$ & $-.068(.029)$ & $-.131(.039)$ \\
& Indirect effect & ------- & .174 & .128 \\
& Total effect & .314 & .106 &. .003 \\
Deep approach to learning & Direct effect &.------ & $.555(.026)$ & $-408(.031)$ \\
& Indirect effect & --------- & .408 \\
\hline
\end{tabular}

\section{Discussion}

Taking the higher education as an example, this study aims to explore the relationship among instructors' learning mode, students' learning engagement, and student learning outcomes by SEM. There are two reasons for this study to explore the subject of this research structure: the theoretical level and the practical level. On the theoretical level, in the past research on DAL constructs, the roles of instructors are rarely included in the discussion, and besides, the learning process of stimulus $\rightarrow$ cognition $\rightarrow$ outcomes in the cognitive learning theory is applied to this research framework, and DAL constructs play an important role between learning modes and student learning outcomes. On the practical level, what most people criticize is that learning is not used in practices, because students have a low learning aspiration, which causes low learning outcomes. However, the reason for the lack of motivation for learning is diversified. From the view of university, the most important factors are the instructors' learning modes and styles. Therefore, how to attract students to DAL through effective learning modes and demonstrate high learning outcomes is the focus of this study.

\section{The Influence of Exploitative Learning on Deep Approach to Learning}

This study assumes that instructors' use of both exploitative learning and explorative learning contributes to the building of DAL, and the results also support this hypothesis. Instructors, no matter through exploitative learning or explorative learning, can lead students into a deep-thinking learning environment and help students integrate and reflect on information and knowledge of the curriculum to enhance their engagement in the curriculum. The results are consistent with those of Campbell and Cabrera (2014), Biggs and Tang (2011), Hmelo-Silver et al. (2007) and Li et al. (2007). All teaching processes are 
able to lead students into more complex cognitive levels, learn the relevance between ideas, and understand learning materials in a wider range. Furthermore, from the verification of the structural model, it is found that the exploitative learning has a greater coefficient value for DAL than the explorative learning. This shows that the exploitative learning emphasizes the combination of real-world events and curriculum information and helps students to create new ideas, integrate and analyse information, and reflect on the relevance of information to provide insights. The difference between this study and the study of Campbell and Cabrera (2014), Laird et al. (2006, 2008) is that this study deeply discusses the learning modes that lead student to DAL by constructing a complete structural model, which will bring meaningful opinions for future studies on DAL.

\section{The Relationship among Exploitative Learning, Explorative Learning and Student Learning Outcomes}

This study infers that instructors' use of both exploitative learning and explorative learning modes can help students improve their learning outcomes (cognitive and non-cognitive gains). The results of the study support the hypothesis that there is a positive relationship between exploitative learning and student learning outcomes. However, although the explorative learning and student learning outcomes are statistically significant, a negative relationship is shown, indicating that the instructor's use of the explorative learning will reduce the student learning outcomes. With regard to the exploitative learning, the results are consistent with the findings of Pike et al. (2011), and Li et al (2007). That is, if instructors have rich experience in educational practice, what they impart to student is not only the knowledge on course materials, but also the practical experience of instructors, resulting in students' initiative learning. This indicates that the information processing and critical thinking modes in the real world can arouse students' interest in learning. As Holland's person-environment theory put forward by Pike et al. (2012), the interaction between instructor teaching and student learning is a social process that relatively improves the work satisfaction, work attitude and expectations for learning of students. Similarly, this study agrees with Kobet's model proposed by Corbett (2005), believing that the exploitative learning creates assimilative and convergent knowledge circularly through the transformation of concrete experience, reflective observation, abstract conceptualization and active experimentation, and thus improve the learning outcomes.

However, it is interesting that the use of explorative learning by instructors has a negative impact on the student learning outcomes. The results of this study are in contrast to that of Philip et al. (2008), who believe that explorative learning can improve students' learning outcomes. The possible causes may be explained by the surface approach to learning mode that held by Marton and Säljö (1976), Campbell and Cabrera (2014). The mode indicates that the instructor's teaching contents need to guide students to learn professional knowledge. If these contents emphasize recitation and when the course study is highly coherent, it is easy to reduce students' understanding and cohesion of the curriculum knowledge, thereby reducing the gains of explorative learning. According to the self-consistency theory, when students have lower academic self-concept, they will try to escape from learning and make the least effort. These psychological defence mechanisms to escape from failure provide only temporary cognition and will ultimately affect learning and even make students stay away from learning.

\section{The Meaning and Mediating Role of Deep Approach to Learning in the Student Learning Outcomes}

This study assumes that there is a positive relationship between the degree of student engagement in DAL and the student learning outcomes (cognitive gains and non-cognitive gains). The results verify this hypothesis. When students have higher levels of higher-order learning, integrative learning and reflective 
learning, the student learning outcomes will be improved. The findings are consistent with those concluded by scholars such as Biggs and Tang (2011), Campbell and Cabrera (2014), Laird et al. (2008), Maringe and Sing (2014), and Pascarella et al. (2013). Students are encouraged to use the DAL to the course materials to develop a highly critical writing, and conceptualized ideas are applied to the design of research issues and the empirical investigations. However, the coefficient values of the structural model show that the DAL has a greater impact on cognitive gains than on non-cognitive gains. This study finds that Taiwan's higher education institutions do not pay enough attention to the general education, and curriculum planning has not been designed to develop the social adaptability, ethical value and soft skills. In addition, education resources continue to shrink, and some job markets are also shrinking, because the government's investment in education funds runs behind the education expenses. All universities are promoting professional projects with good prospects for development to increase the academic rigour, which increases the instructors' workload (Campbell \& Cabrera, 2014), and indirectly reduces students' understanding and cognition of morality, values and self-beliefs.

This study further verifies the role of DAL in the research framework, and its research results also indicate that it has a high degree of mediating effects. The study finds that the DAL has a complete mediating effect between explorative learning and student learning outcomes but has a partial mediating effect between exploitative learning and student learning outcomes. In other words, instructors' teaching may not be able to significantly enhance students' learning outcomes by the explorative learning, but they can achieve learning outcomes by cultivating the learning traits and scenarios of students such as the use of learning mode or the involvement in learning activities (Petersen, Louw, \& Dumont, 2009). Students need not only to learn theoretical knowledge, but also learn to face a phenomenon or problem, consider the origin of the problem and the meaning behind it, and then use theories to define problems or phenomena, and ultimately solve the problem by the operation of knowledge.

\section{Educational implications}

According to research discussions and findings, this study proposes several suggestions for the reference by education practitioners to improve the development of higher education in China. First of all, this study suggests university instructors to plan the case-oriented, peer interaction or practical drill learning mode in the application of curriculum design, guide students to participate in learning, and use the knowledge of relevant disciplines, instead of recitation, as explanatory supplements during the example interpretation or common discussions. This can promote students to achieve higher learning outcomes. In addition, instructors are encouraged to try teaching innovation, use explorative and exploitative learning mode in appropriate courses, and then use activity exercises and homework assignments to improve the connection between students' professional knowledge and practical applications.

Second, the study suggests that universities should continue to strengthen students' practical learning and career development mechanisms, offer job career planning courses, guide students in selfexploration, career planning, and encourage instructors to master social development and workplace situations, emphasize the integration and innovation of cross-disciplinary knowledge, and increase case guidance and practice sharing. Besides, universities should be committed to strengthening the link between students' learning history and workplace experience, and developing students' abilities to solve problems, make decisions, and have critical thinking, except for inducing student self-study, interest and motives.

Third, the DAL can shape high-quality university teaching practice (Biggs \& Tang, 2011; Ramsden, 2003; Tagg, 2003). The development process of such teaching practice lies in the cooperation of students, colleges, universities and instructors, with the purpose of developing in-depth and concrete learning mode, 
such as inducing positive student responses, building students' prior knowledge, and teaching the interconnection of broader ideas and ideas (Biggs \& Tang, 2011; Campbell \& Cabrera, 2014). Therefore, this study proposes to establish an alliance team between the institutes to jointly solve problems, consider the most suitable solutions with different professions, and strengthen communication, coordination and teamwork with each other, stimulate ideas and links between each, thereby improving learning outcomes.

\section{Limitations and future research directions}

Although this study has contributed to curriculum and teaching, cognitive learning theory, DAL and student learning outcomes, there are still some limitations that are worth further analysis by future researchers to compensate for theoretical deficiencies. First of all, the previous analysis on the structural validity of the DAL has achieved considerable development and contribution, but few studies have regarded it as a mediating variable to explore its role in student learning outcomes. Although this study uses cognitive learning theory to construct the learning modes, including exploitative learning and explorative learning, its research results make important contributions to student learning theories.

However, some other learning theories applicable for explaining how to guide students to develop DAL and enhance student learning are still available. Examples include attribution theory, self-efficacy theory, demand hierarchy theory, etc. Therefore, future researches can follow different theoretical models and construct relevant prior variables and outcome variables that affect students' DAL. Second, this study requires participants to fill in their academic achievement as an indicator of academic performance. This is mainly because the actual academic achievement is private and not easily accessible. However, there may be some errors in the memories of academic achievement. If we can collect students' actual academic achievement in consideration of research ethics, we may be able to better understand the relationship between instructors' learning modes and academic achievement.

Third, the participants in this study come from only 16 universities, so the samples can be expanded in the future to improve the representation. It is also possible to extend the samples to student groups outside the university, for understanding and comparison. Last but not least, this study uses the correlation research method, and cannot fully determine the causality between variables. In the future, experiments or other methods can be used again to confirm the causality between variables. For the same reason, this study cannot clearly define complex causal patterns such as the backtracking or cycle effect of cross time-series. In the future, longitudinal information can be collected for specific groups to better understand the interactions between variables.

\section{References}

Astin, A. W. (1993). An empirical typology of college students. Journal of College Student Development, $34(1), 36$ 46.

Bagozzi, R. P., \& Yi, Y. (1988). On the evaluation of structural equation models. Journal of the Academy of Marketing Science, 16(1), 74 - 94. https://doi.org/10.1007/BF02723327

Beatie, V., Collins, B., \& McInnes, B. (1997). Deep and surface learning: A simple or simplistic dichotomy. Accounting Education, 6(1), 1 - 12. https://doi.org/10.1080/096392897331587

Biggs, J. (2003). Teaching for Quality Learning at University (2nd ed). Buckingham: SRBE and Open University Press

Biggs, J., \& Tang, C. (2011). Teaching for quality learning at university: What the student does. UK: McGraw-Hill Education

Biggs, J., Kember, D., \& Leung, D. Y. (2001). The revised two-factor study process questionnaire: R-SPQ-2F. British Journal of Educational Psychology, 71(1), 133 - 149. https://doi.org/10.1348/000709901158433 
Campbell, C. M., \& Cabrera, A. F. (2014). Making the mark: Are grades and deep learning related? Research in Higher Education, 55(5), 494 - 507. https://doi.org/10.1007/s11162-013-9323-6

Chen, S.-W., Wang, H.-H., Wei, C.-F., Fwu, B.-J., \& Hwang, K.-K. (2009). Taiwanese students' self-attributions for two types of achievement goals. The Journal of Social Psychology, 149(2), 179 - 194. doi: 10.3200/SO CP.149.2.179-194

Choi, B. K., \& Rhee, B. S. (2014). The influences of student engagement, institutional mission, and cooperative learning climate on the generic competency development of Korean undergraduate students. Higher Education, 67(1), 1 - 18. doi: 10.1007/s10734-013-9637-5

Cole, M. S., Feild, H. S., \& Harris, S. G. (2004). Student learning motivation and psychological hardiness: Interactive effects on students' reactions to a management class. Academy of Management Learning \& Education, 3(1), 64 - 85. http://dx.doi.org/10.5465/AMLE.2004.12436819

Corbett, A. C. (2005). Experiential learning within the process of opportunity identification and exploitation. Entrepreneurship Theory and Practice, 29(4), 473 - 491. https://doi.org/10.1111/j.1540-6520.2005.00094.x

Greene, B. A., Miller, R. B., Crowson, H. M., Duke, B. L., \& Akey, K. L. (2004). Predicting high school students' cognitive engagement and achievement: Contributions of classroom perceptions and motivation. Contemporary Educational Psychology, 29(4), 462 - 482. http://dx.doi.org/10.1016/j.cedpsych.2004.01.006

Guay, F., Ratelle, C. F., \& Chanal, J. (2008). Optimal learning in optimal contexts: The role of self-determination in education. Canadian Psychology/Psychologie Canadienne, 49(3), 233 - 240. doi: 10.1037/a0012758

Hair, J. F., Black, W. C., Babin, B. J., \& Anderson, R. E. (2010). Multivariate data analysis: A global perspective. Upper Sadder River, NJ: Prentice-Hall.

Hau, K. T., \& Marsh, H. W. (2004). The use of item parcels in structural equation modelling: Non-normal data and small sample sizes. British Journal of Mathematical and Statistical Psychology, 57(2), 327 - 351.

Hmelo-Silver, C. E., Duncan, R. G., \& Chinn, C. A. (2007). Scaffolding and achievement in problem-based and inquiry learning: A response to Kirschner, Sweller, and Clark (2006). Educational Psychologist, $42(2), 99$ - 107. doi:10.1080/00461520701263368

Hummel, E., \& Randler, C. (2012). Living animals in the classroom: A meta-analysis on learning outcome and a treatment-control study focusing on knowledge and motivation. Journal of Science Education and Technology, 21(1), 95 - 105. doi: 10.1007/s10956-011-9285-4

Jöreskog, K. G., \& Sörbom, D. (1993). LISREL 8: Structural equation modelling with the SIMPLIS command language. Chicago: Scientific Software International.

Kolb, D. A. (1984). Experiential learning: Experience as the source of learning and development. Englewood Cliffs, NJ: Prentice Hall.

Kuh, G. D., Kinzie, J., Buckley, J. A., Bridges, B. K., \& Hayek, J. C. (2006). What matters to student success: A review of the literature commissioned report for the national symposium on postsecondary student success: Spearheading a dialog on student success. Washington DC: National Postsecondary Education Cooperative.

Li, T., Greenberg, B. A., \& Nicholls, J. (2007). Teaching experiential learning: Adoption of an innovative course in an MBA marketing curriculum. Journal of Marketing Education, 29(1), 25 - 33. https://doi.org/10.1177/027347 5306297380

Liem, A. D., Lau, S., \& Nie, Y. (2008). The role of self-efficacy, task value, and achievement goals in predicting learning strategies, task disengagement, peer relationship, and achievement outcome. Contemporary Educational Psychology, 33(4), 486 - 512. http://dx.doi.org/10.1016/j.cedpsych.2007.08.001

Little, T. D. (1997). Mean and covariance structures analyses of cross-cultural data: Practical and theoretical issues. Multivariate Behavioural Research, 32(1), 53 - 76. https://doi.org/10.1207/s15327906mbr3201_3

Little, T. D., Cunningham, W. A., Shahar, G., \& Widaman, K. F. (2002). To parcel or not to parcel: Exploring the question, weighing the merits. Structural Equation Modelling, 9(2), 151 - 173. http://dx.doi.org/10.1207/S1 5328007SEM0902_1

Laird, T. F. N., Shoup, R., \& Kuh, G. D. (2006). Measuring deep approaches to learning using the National Survey of Student Engagement. Paper presented at the annual meeting of the Association for Institutional Research.

Laird, T. F. N., Shoup, R., Kuh, G. D., \& Schwarz, M. J. (2008). The effects of discipline on deep approaches to student learning and college outcomes. Research in Higher Education, 49(6), 469 - 494. https://doi.org/10.1007/ s11162-008-9088-5

Marginson, S. (2011). Higher education and public good. Higher Education Quarterly, 65(4), 411 - 433. https://doi.org/10. 1111 /j.1468-2273. 2011.00496.x

Maringe, F., \& Sing, N. (2014). Teaching large classes in an increasingly internationalising higher education environment: pedagogical, quality and equity issues. Higher Education, 67(6), 761 - 782. doi: 10.1007/s107 34-013-9710-0 
Marton, F., \& Säljö, R. (1976). On qualitative differences in learning: I-Outcome and process. British Journal of Educational Psychology, 46(1), 4 - 11. https://doi.org/10.1111/j.2044-8279.1976.tb02980.x

Nespor, J. (1987). The role of beliefs in the practice of teaching. Journal of Curriculum Studies, $19(4), 317$ - 328. https://doi.org/10.1080/0022027870190403

Oleson, A., \& Hora, M. T. (2014). Teaching the way they were taught? Revisiting the sources of teaching knowledge and the role of prior experience in shaping faculty teaching practices. Higher Education, 68(1), 29 - 45. doi 10.1007/s10734-013-9678-9

Pace, C. R. (1984). Measuring the quality of college student experiences. Los Angeles: Centre for the Study of Evaluation, University of California Los Angeles.

Pascarella, E. T., \& Terenzini, P. T. (1991). How college affects students. Findings and insights from twenty years of research. San Francisco: Jossey-Bass.

Pascarella, E. T., \& Terenzini, P. T. (2005). How college affects students: Vol. 2 A decade of research. San Francisco: Wiley.

Pascarella, E. T., Wang, J.-S., Trolian, T. L., \& Blaich, C. (2013). How the instructional and learning environments of liberal arts colleges enhance cognitive development. Higher Education, 66(5), 569 - 583. doi: 10.1007/s10734-013-9622-z

Petersen, I. H., Louw, J., \& Dumont, K. (2009). Adjustment to university and academic performance among disadvantaged students in South Africa. Educational Psychology, 29(1), 99 - 115. https://doi.org/10.1080/ 01443410802521066

Philip, C. T., Unruh, K. P., Lachman, N., \& Pawlina, W. (2008). An explorative learning approach to teaching clinical anatomy using student generated content. Anatomical Sciences Education, 1(3), 106 - 110. https://doi.org/10. $1002 /$ ase. 26

Pike, G. R., Kuh, G. D., McCormick, A. C., Ethington, C. A., \& Smart, J. C. (2011). If and when money matters: The relationships among educational expenditures, student engagement and students' learning outcomes. Research in Higher Education, 52(1), 81 - 106. doi: 10.1007/s11162-010-9183-2

Pike, G. R., Smart, J. C., \& Ethington, C. A. (2012). The mediating effects of student engagement on the relationships between academic disciplines and learning outcomes: An extension of Holland's theory. Research in Higher Education, 53(5), 550 - 575. doi: 10.1007/s11162-011-9239-y

Pike, G. R., Smart, J. C., Kuh, G. D., \& Hayek, J. C. (2006). Educational expenditures and student engagement: When does money matter? Research in Higher Education, 47(7), 847 - 872. doi: 10.1007/s11162-006-9018-3

Preacher, K. J., \& Hayes, A. F. (2004). SPSS and SAS procedures for estimating indirect effects in simple mediation models. Behaviour Research Methods, Instruments, \& Computers, 36(4), 717 - 731. https://doi.org/10.3758/ BF03206553

Ramsden, P. (2003). Learning to teach in higher education. London: Routledge.

Reason, R. D., Cox, B. E., McIntosh, K., \& Terenzini, P. T. (2010). Deep learning as an individual, conditional, and contextual influence on first-year student outcomes. Association for Institutional Research (NJ1).

Schaufeli, W. B., \& Salanova, M. (2007). Efficacy or inefficacy, that's the question: Burnout and work engagement, and their relationships with efficacy beliefs. Anxiety, Stress, and Coping, 20(2), 177 - 196. doi: 10.1080/ 10615800701217878

Schaufeli, W. B., Salanova, M., González-Romá, V., \& Bakker, A. B. (2002). The measurement of engagement and burnout: A two sample confirmatory factor analytic approach. Journal of Happiness Studies, $3(1), 71$ - 92. https://doi.org/10. 1023/A:1015630930326

Shin, J. C., \& Harman, G. (2009). New challenges for higher education: Global and Asia-Pacific perspectives. Asia Pacific Education Review, 10(1), 1 - 13. doi 10.1007/s12564-009-9011-6

Shrout, P. E., \& Bolger, N. (2002). Mediation in experimental and nonexperimental studies: new procedures and recommendations. Psychological Methods, 7(4), 422 - 445. doi: 10.1037//1082-989X.7.4.422

Smart, J. C., Feldman, K. A., \& Ethington, C. A. (2000). Academic disciplines: Holland's theory and the study of college students and faculty. Nashville, TN: Vanderbilt University Press.

Snyder, B. R. (1971). The hidden curriculum. Cambridge, MA: MIT Press.

Sobel, M. E. (1982). Asymptotic confidence intervals for indirect effects in structural equation models. In S. Leunhart (ed.), Sociological Methodology (pp. 290-312). San Francisco, CA: Jossey-Bass.

Tagg, J. (2003). The learning paradigm college. Bolton, MA: Anker Publishing.

Taylor, B. J., Webber, K. L., \& Jacobs, G. J. (2013). Institutional research in light of internationalization, growth, and competition. New Directions for Institutional Research, 2013(157), 5 - 22. https://doi.org/10.1002/ir.20036 
Tella, A. (2007). The impact of motivation on student's academic achievement and learning outcomes in mathematics among secondary school students in Nigeria. Eurasia Journal of Mathematics, Science \& Technology Education, 3(2), 149 - 156. https://doi.org/10.12973/ejmste/75390

Terenzini, P. T., \& Pascarella, E. T. (1991). Twenty years of research on college students: Lessons for future research. Research in Higher Education, 32(1), 83 - 92. https://doi.org/10.1007/BF00992835

White, K. M., Thomas, I., Johnston, K. L., \& Hyde, M. K. (2008). Predicting attendance at peer-assisted study sessions for statistics: Role identity and the theory of planned behaviour. The Journal of Social Psychology, 148(4), 473 - 492. doi: 10.3200/SOCP.148.4.473-492 


\section{Appendix}

Scales

\begin{tabular}{|c|c|c|}
\hline Construct & Variables & Items \\
\hline \multirow{8}{*}{$\begin{array}{l}\text { Explorative } \\
\text { learning }\end{array}$} & \multirow{8}{*}{$\begin{array}{l}\text { Explorative learning } \\
(\alpha=.94)\end{array}$} & Understanding the definition of professional knowledge. \\
\hline & & Understanding the extent of professional knowledge that has been acquired. \\
\hline & & Knowing subjects related to the professional knowledge. \\
\hline & & Knowing the test methods required in face of professional knowledge. \\
\hline & & $\begin{array}{l}\text { Capable of defining the expected value and its costs on a professional } \\
\text { problem. }\end{array}$ \\
\hline & & $\begin{array}{l}\text { Capable of using different problem diagnosis modes for a professional } \\
\text { problem. }\end{array}$ \\
\hline & & $\begin{array}{l}\text { Capable of considering all scenarios and putting forward solutions in face } \\
\text { of a professional problem. }\end{array}$ \\
\hline & & Capable of identifying the severity of a problem. \\
\hline \multirow{9}{*}{$\begin{array}{l}\text { Exploitative } \\
\text { learning }\end{array}$} & \multirow{2}{*}{$\begin{array}{l}\text { Career preparation } \\
(\alpha=.80)\end{array}$} & In developing career skills. \\
\hline & & In serving as a good surrogate for real world experience. \\
\hline & \multirow{3}{*}{$\begin{array}{l}\text { Traditional } \\
\text { educational goals } \\
(\alpha=.87)\end{array}$} & $\begin{array}{l}\text { In helping me understand the material. } \\
\text { In achieving: "I learn a lot". }\end{array}$ \\
\hline & & In improving my competences in this area. \\
\hline & & In achieving high educational value overall. \\
\hline & \multirow{2}{*}{$\begin{array}{l}\text { Use of time } \\
(\alpha=.80)\end{array}$} & In making good use of class time. \\
\hline & & In achieving benefits to time ratio. \\
\hline & \multirow{2}{*}{$\begin{array}{l}\text { Personal } \\
\text { involvement and } \\
\text { satisfaction } \\
(\alpha=.75)\end{array}$} & In producing a high level of involvement. \\
\hline & & In achieving overall satisfaction. \\
\hline \multirow{10}{*}{$\begin{array}{l}\text { Deep } \\
\text { approach to } \\
\text { learning }\end{array}$} & \multirow{4}{*}{$\begin{array}{l}\text { Higher-order } \\
\text { learning } \\
(\alpha=.89)\end{array}$} & $\begin{array}{l}\text { Analysed the basic elements of an idea, experience, or theory, such as } \\
\text { examining a particular case or situation in depth and considering its } \\
\text { components. }\end{array}$ \\
\hline & & $\begin{array}{l}\text { Synthesized and organized ideas, information, or experiences into new, } \\
\text { more complex interpretations and relationships. }\end{array}$ \\
\hline & & $\begin{array}{l}\text { Made judgments about the value of information, arguments, or methods, } \\
\text { such as examining how others gathered and interpreted data and assessing } \\
\text { the soundness of their conclusions. }\end{array}$ \\
\hline & & Applied theories or concepts to practical problems or in new situations. \\
\hline & \multirow{5}{*}{$\begin{array}{l}\text { Integrative learning } \\
(\alpha=.79)\end{array}$} & $\begin{array}{l}\text { Worked on a paper or project that required integrating ideas or information } \\
\text { from various sources. }\end{array}$ \\
\hline & & $\begin{array}{l}\text { Included diverse perspectives (different races, religions, genders, political } \\
\text { beliefs, etc.) in class discussions or writing assignments. }\end{array}$ \\
\hline & & $\begin{array}{l}\text { Put together ideas or concepts from different courses when completing } \\
\text { assignments or during class discussions. }\end{array}$ \\
\hline & & $\begin{array}{l}\text { Discussed ideas from your readings or classes with faculty members } \\
\text { outside of class. }\end{array}$ \\
\hline & & $\begin{array}{l}\text { Discussed ideas from your readings or classes with others outside of class } \\
\text { (students, family members, co-workers, etc.). }\end{array}$ \\
\hline & $\begin{array}{l}\text { Reflective learning } \\
(\alpha=.77)\end{array}$ & $\begin{array}{l}\text { Examined the strengths and weaknesses of your own views on a topic or } \\
\text { issue. } \\
\text { Tried to better understand someone else's views by imagining how an issue } \\
\text { looks from his or her perspective. }\end{array}$ \\
\hline
\end{tabular}


Acquiring a broad general education.

Acquiring job or work-related knowledge and skills.

Writing clearly and effectively.

Cognitive gains Speaking clearly and effectively.

$(\alpha=.86)$

Thinking critically and analytically.

Analysing quantitative problems.

Student

learning

Using computing and information technology.

outcome

Learning effectively on your own.

Solving complex real-world problems.

Working effectively with others.

Voting in local, state, or national elections.

Non-cognitive gains Understanding yourself.

$(\alpha=.84)$

Understanding people of other racial and ethnic backgrounds.

Developing a personal code of values and ethics.

Contributing to the welfare of your community.

Developing a deepened sense of spirituality.

All items mentioned above use the Likert 7 -point scale $(1=$ totally disagree $; 7=$ totally agree $)$. 